\title{
A MEDIAÇÃO AMBIENTAL INTERNACIONAL E A ÉTICA DA RESPONSABILIDADE
}

\author{
Simone Alves Cardoso* \\ Adriana Machado Yaghsisian**
}

\section{RESUMO}

Os conflitos ambientais internacionais que marcam a sociedade pós-moderna são complexos, dinâmicos e rompem os conceitos tradicionais de fronteiras, e, por isso, apontam para novas formas de solução. Tais formas são aquelas que deverão levar em conta a participação de novos atores, que atuarão apoiados por uma ética de responsabilidade, segundo Hans Jonas, que valoriza a dignidade e as relações inter-humanas, em constante interação com o meio ambiente. Diante dessa dinâmica, deve-se buscar por métodos de solução de conflitos ambientais internacionais que atendam a modernidade líquida e permita a maior participação das partes envolvidas.

Palavras-chave: mediação - conflitos ambientais- ética da responsabilidade - direito internacional ambiental

\section{INTERNATIONAL ENVIRONMENTAL MEDIATION AND THE ETHICS OF RESPONSABILITY}

\begin{abstract}
International environmental conflicts that marked postmodern society are complex, dynamic and break with traditional borders concepcts, pointing out, for this reason, to new solution mechanisms. These mechanisms are the ones that take into account the participation of new actors, whom will act suported by an ethic of responsability, according to Hans Jonas, who values dignity and inter-humans relations in continuous interaction with environment. Regarding this dynamic, it is necessary to seek new resolution methods for international

\footnotetext{
* Doutora em Direito Ambiental Internacional pela Universidade Católica de Santos (2017), mestre em Direito Urbanístico pela Pontifícia Universidade Católica de São Paulo (2004) e graduada em Direito pela Universidade de Franca (2000). Associada individual da Environmental Peacebuilding Association. Professora de direito ambiental e mediação na graduação da Faculdade de Direito da Universidade Católica de Santos. Mediadora e Coordenadora do Curso de Extensão de Capacitação de Conciliadores e Mediadores e do Curso de Especialização em Mediação, Resolução de Conflitos e Cultura de Paz ambos da Unisantos. Integra o grupo de pesquisa em Resolução de Conflitos Socioambientais e o grupo de Energia e Meio Ambiente do programa de Pós-gradução Mestrado e Doutorado da Unisantos. Endereço postal: Rua Tolentino Filgueiras, n.165/82, Santos/SP e e-mail: sacardoso75@gmail.com.

** Possui graduação em Direito pela Universidade Católica de Santos (1994), mestrado em Direitos Difusos e Coletivos pela Universidade Metropolitana de Santos (2004) e doutorado em Direito Ambiental Internacional pela Universidade Católica de Santos. Integra o grupo de pesquisa em Energia e Meio Ambiente, do grupo de pesquisa em Resolução de Conflitos Socioambientais e do grupo de pesquisa em Direitos Humanos, da Pós-gradução Mestrado e Doutorado da Unisantos. Atualmente é professora do curso de Direito da Universidade Católica de Santos, nas disciplinas de Direito Civil, Prática Jurídica Civil e Conciliação, Mediação e Arbitragem, além de atuar como instrutora do Curso de Extensão, de Capacitação de Conciliadores e Mediadores da Unisantos certificada pelo TJ/SP.E-mail: adrianamachado4@ gmail.com.
} 
environmental conflicts that meets the liquid modernity and that allows major participation of parties involved.

Key words: mediation - environmental conflicts - ethics of responsibility - international environmental law

\section{INTRODUÇÃOO}

A complexidade dos conflitos ambientais, marcados pelo desenvolvimento acelerado de novas tecnologias, levou ao crescimento econômico, porém comprometeu o equilíbrio ambiental, e desencadeou consequências como mudanças climáticas, escassez de recursos naturais, migrações forçadas e diversos outros problemas, que demandam um ajuste sustentável e cooperativo entre vários atores, na busca de soluções pacificadoras.

O direito ao meio ambiente e a paz social devem ser abordados sob a ótica do Direito Internacional e da indivisibilidade dos direitos humanos, em sintonia com os direitos econômicos, sociais e culturais.

Tal concepção nos conduz ao direito ao desenvolvimento, o que exige uma globalização ética e solidária, em que a pessoa humana é o sujeito central do desenvolvimento e deve ser ativa, participativa e beneficiária do direito ao desenvolvimento.

Nessa perspectiva, a implementação de ações voltadas à cultura da mediação é importante, pois a sua prática poderá fomentar a ética da responsabilidade, alcançar o desenvolvimento sustentável e promover a construção de soluções pacíficas dos conflitos ambientais internacionais.

Com este ideário, o presente artigo visa, primeiramente, as características dos conflitos ambientais internacionais. Em seguida, aponta a importância da formação de rede de mediadores, característica da modernidade líquida (BAUMAN, 2001), que permite a mediação fluir entre diversos níveis.

Por fim, aborda alguns conceitos de mediação e seu desenvolvimento no contexto internacional, focando na contribuição da mediação ambiental internacional para o despertar da ética da responsabilidade de Hans Jonas.

A metodologia do trabalho está embasada na teoria crítica dialética, com viés indutivo, visando o exame do dinamismo das relações sociais que envolvem a mediação internacional e a participação do cidadão na construção da paz ambiental, inseridas em uma realidade histórica, em que as alterações de ideologias por que passa a sociedade são enxergadas como parte de um processo de transição. 


\section{Conflitos ambientais internacionais}

Segundo destaca Carson (2010), a história da vida na Terra foi marcada por uma interação entre os seres vivos e seu ambiente. Nessa lógica, a forma física e os hábitos da vegetação e da vida animal terrestre foram sendo moldados pelo meio ambiente, em grande parte. No século XX, a vida passou a modificar, na prática, seu ambiente quando uma das espécies, o ser humano, começou a atuar com poder significativo na natureza do seu mundo.

Esse poder, ao longo do século anterior, agigantou-se e mudou de caráter, constituindo a contaminação do ar, do solo, dos rios e dos mares, com materiais perigosos e até letais, marca cruel dos ataques do ser humano.

Neste século, há crescente clamor para a proteção ambiental, fundada em razões antropocêntricas ou ecocêntricas. A proteção ambiental internacional pode ser dividida em quatro fases. A primeira, do fim do século XIX ao final da Segunda Guerra Mundial. A segunda, de 1945 a 1972. A terceira, da Conferência de Estocolmo, de 1972, à Conferência do Rio, de 1992, e a quarta fase, da Conferência do Rio 92 até os dias atuais. Com efeito, no primeiro estágio, as regras internacionais tinham preocupações especiais na proteção da fauna e flora, além da abordagem antropocêntrica e utilitária. No segundo estágio, por seu turno, a criação das Nações Unidas e suas agências especializadas promoveram conflitos direta ou indiretamente relacionados à proteção ambiental. A Conferência de Estocolmo marca o terceiro estágio, evidenciando o tema do meio ambiente humano, cuja ocasião sucedia a Declaração dos EUA sobre o ambiente e a aprovação do Plano de Ação Ambiental, além do lançamento do programa ambiental das Nações Unidas (UNEP). Na Rio 92, que marca o início da quarta fase, propõe-se uma nova definição formal de desenvolvimento sustentável.

As causas dos conflitos são múltiplas e complexas: as tensões fronteiriças e interétnicas, a exclusão social e as lutas pelo controle dos recursos naturais, entre outras. Sabemos que os tecidos sociais, uma vez rotos, podem demorar várias gerações para se recompor. Sabemos também que com uma pequena parte dos fundos que se gasta anualmente em armas de guerra pode-se estabelecer mecanismos de consulta e consenso que diminuam a possibilidade de morte e destruição. Por mais simples que pareça, trata-se de ver os sinais insipientes de um conflito violento e tentar chegar a tempo. 
E é nesse contexto que se colocam os conflitos ambientais, que podem ser conceituados como a disputa social que ocorre quando alguém tem determinada pretensão em fazer uso de certo recurso natural e o outro cria uma barreira, de modo a impedir ou de regulamentar essa conduta. Eles podem ser divididos em dois tipos: a) conflitos de uso, nos quais ocorre a disputa entre particulares, ou de particulares com o poder público, que têm intuito de fazer uso de certo bem ou recurso do meio ambiente; b) conflitos entre empreendedores, tanto públicos quanto privados, que têm como objetivo a exploração dos recursos ambientais com a comunidade, que, por sua vez, visa à preservação ou a sua conservação (ERNANDORENA, 2012).

Mas os conflitos não devem ser vistos de modo negativo. Lund (1999) reconhece que os conflitos sociais são comuns e até desejáveis. Para ele, a maneira de encontrar soluções em uma sociedade democrática parte da contraposição de pontos de vista de diferentes setores, que, ao final, se enfrentam e debatem suas posturas para tomar a decisão mais acertada frente a qualquer assunto público.

Diante desse complexo contexto que se desenha, associado à magnitude transnacional das causas e efeitos dos problemas ambientais, demanda-se que a proteção do meio ambiente passe a integrar a preocupação dos Estados, organizações e instituições internacionais governamentais e não governamentais, além da própria sociedade civil, a fim de que alcancemos sociedades mais resilientes e prósperas.

E para atender a essa delicada e difícil relação da sociedade pós-moderna, o direito ambiental mostra-se consentâneo, considerando-se que constitui um dos ramos mais recentes do regramento jurídico internacional. A capacidade que apresenta de aglutinar uma normativa cada vez mais ampla, diversificada e complexa, tem sido decisiva para tal aderência (KISS, 2007).

Sensíveis à gravidade dos problemas que afetam o meio ambiente comum, os Estados têm exercido uma percepção voltada à necessidade de cooperar em busca de soluções. Segundo destaca Ruiz (2014), três são os fatores que põem em evidência a internacionalização dos problemas ambientais e a necessidade de cooperação em direção às resoluções correspondentes, a saber: a contaminação transfronteiriça, a exportação dos riscos ou mundialização dos problemas ambientais e a crescente globalização do sistema econômico.

Nessa perspectiva, e visando equacionar tais questões internacionais, a cooperação se põe com novel espírito. Constituindo um dos primeiros princípios do direito ambiental 
internacional, foi proclamada na Declaração de Estocolmo, de 1972, em seu princípio 22, e na Declaração do Rio, cujo artigo 24 assim estabelece: “todos os países, grandes e pequenos, devem ocupar-se com espírito de cooperação e em pé de igualdade com as questões internacionais relativas a proteção e melhoramento do meio ambiente".

E, para a eficiência no processo de cooperação internacional, a ampliação dos atores envolvidos é sua conditio sine qua non. Nessa ótica, não basta a atuação dos Estados, isoladamente, constitui nota marcante a participação concertada das ONG's, que passam progressivamente a adquirir status e integrar os processos de elaboração e aplicação do direito internacional do meio ambiente (KISS, 2007).

Na mesma intensidade, verifica-se sensível crescimento da participação das pessoas nas questões ambientais, em decorrência do processo de fortalecimento do direito de acesso à informação.

Todavia, o insuficiente grau de cumprimento das normas provenientes do direito ambiental internacional tem sido um obstáculo à concretização dessa ação concertada. Segundo Ruiz (2014, p. 90), essa situação "resulta da falta de instituições capazes de assegurar uma governança multilateral”. Atualmente, o Programa das Nações Unidas para o Meio Ambiente (PNUMA), criado pela Conferência de Estocolmo, de 1972, é o organismo que se ocupa dessa questão ${ }^{1}$, tendo, como função importante, entre outras, promover a cooperação internacional no âmbito do meio ambiente e recomendar políticas nessa matéria.

A integração dos princípios da cooperação, da vedação do uso da força para solução de litígios, em matéria ambiental, juntamente com o fortalecimento da mediação de conflitos ambientais aponta para a construção e a consolidação da paz ambiental.

\section{A formação de rede de mediadores na modernidade líquida}

Inicialmente, o tema resolução de conflitos focou na atividade política realizada por representantes políticos que atuavam em nome dos Estados. Nessa dinâmica, os mediadores eram, em geral, diplomatas, políticos ou outros representantes dos governos ou, ainda, da Igreja. 1 O PNUMA foi criado pela Assembleia Geral da ONU como órgão subsidiário e constitui o principal órgão das
Nações Unidas no âmbito do meio ambiente e desenvolvimento sustentável. 
No início da década de 1970 surge, nos Estados Unidos, com o argumento de ser uma melhor alternativa à litigância, a mediação ambiental. Países como Canadá, Itália, GrãBretanha, Alemanha e Holanda têm experiência na mediação ambiental, seguindo a realidade americana. Igualmente, ocorre no Leste e Centro europeus. Entre os argumentos, aponta-se o fato consistente de que ela pode produzir acordos que melhor satisfaçam os interesses das partes quando em confronto com os procedimentos administrativos, consoante destaca Yoshida (2017).

Ao longo das últimas duas décadas, houve um aumento significativo no número e variedade de atores envolvidos em tentativas de evitar, mitigar e resolver os conflitos.

Na sociedade pós-moderna, conflitos sobre o controle do governo, recursos naturais e econômicos são a sua nota característica, o que demanda a existência de uma rede complexa de objetivos e agentes, com dimensões locais, regionais e que transcendam as fronteiras de um país.

Nesse panorama complexo, o envolvimento de novos atores pode assegurar elementos fundamentais, como maior legitimidade, eficácia e equidade na solução final, tendo a mediação papel preponderante para tal fim.

Identificada pelo artigo 33 da Carta das Nações Unidas como um meio de resolução pacífica dos conflitos internacionais, a mediação surge como uma forma de fortalecer a atuação dos atores envolvidos. É um processo através do qual uma terceira parte assiste duas ou mais partes, com seu consentimento, para prevenir, gerir ou resolver um conflito, ajudando as partes a desenvolver mutuamente a aceitação de acordos (ONU, 2017).

Nessa linha, a diplomacia preventiva, a mediação, a implantação de prevenção e manutenção da paz e as atividades inclusivas de Consolidação da Paz, após o conflito, são indissociáveis e atuam de forma interdependente.

Segundo o Manual da ONU sobre Mediação, um processo eficaz de mediação depende da natureza do conflito e da preparação e percepção do mediador ou da equipe de mediadores quanto às causas e a dinâmica do conflito, as posições, os interesses das partes, as necessidades da sociedade em geral, no âmbito regional e internacional (ONU, 2012).

E, nessa perspectiva, cabe aos mediadores e suas equipes proporcionarem uma proteção para as partes em conflito e estabelecerem uma aliança baseada na confiança no processo e na crença de que a resolução pacífica é possível. Um bom mediador promove o intercâmbio por meio da escuta ativa e do diálogo, promove o espírito de colaboração por 
meio da resolução de problemas, assegura que as partes em negociação têm suficiente conhecimento, informação e habilidades para negociar com confiança, além de ampliar o processo para incluir as partes interessadas de diferentes segmentos de uma sociedade (ONU, 2012).

Dessa forma, a adequada identificação dos diferentes pontos de vista, necessidades e interesses das partes envolvidas no conflito são preponderantes para a eficácia da mediação. De fato, um processo de mediação bem conduzido aumenta a legitimidade e apropriação nacional do acordo de paz e sua implementação, bem como reduz a probabilidade de atores excluídos enfraquecerem o procedimento. Um processo inclusivo não impõe que todas as partes interessadas participem diretamente das negociações formais, mas, indubitavelmente, facilita a interação entre as partes em conflito e outras partes interessadas, além de criar mecanismos para incluir todas as perspectivas em busca da construção do acordo.

A mediação tem se mostrado efetiva para a solução de conflitos, para alcançar a paz, tanto entre os Estados como dentro de Estados em conflito. Há um voluntário esforço em se utilizar esse método, e suas técnicas, que varia quanto aos objetivos. Algumas vezes, abordase uma específica questão para conter ou gerenciar um conflito, e em outras vezes é necessário abranger um amplo alcance de questões dentro de um compreensivo processo de paz. Tais processos oferecem uma oportunidade crítica para os Estados e sociedades reformularem sua política, segurança e panorama socioeconômico, a fim de estabelecer a fundação para a paz sustentável (ONU, 2017).

E quando se trata de conflito ambiental, a adoção de cautelas para se evitar ou até mesmo minimizar o embate entre a visão desenvolvimentista e a visão ambientalista, que possuem patamares diferentes de exigências em relação aos impactos das atividades econômicas nos meios físico, biótico e antrópico, é essencial para a efetividade da mediação ambiental.

A mediação internacional é tradicionalmente realizada por Estados, embora eles não tenham o monopólio dessa atividade. Além dos Estados, pode-se identificar atores que exercem o papel de mediadores para a paz. São as organizações internacionais, organizações não governamentais e iniciativas individuais.

Recentemente, as organizações regionais e sub-regionais tornaram-se atores ativos na gestão e resolução de conflitos. A mediação tem sido, cada vez mais, apoiada por essas organizações. Nos últimos anos, os atores não estatais, ou atores da diplomacia privada 
(PDA), como mencionado por Marshall (2012), têm fornecido suporte de mediação para pacificadores institucionais ou estatais.

Os conflitos contemporâneos exigem uma mediação Mult-track ${ }^{2}$,que seria a atuação de mediadores em diferentes níveis ou faixas do conflito. O mediador Track 1, como Estado ou organização internacional, tem uma atuação mais política e formal. Ele contribui pouco, no sentido de garantir a apropriação pelas partes do acordo de paz. Já os mediadores não estatais, Track 2, podem atuar de baixo para cima na transformação do sistema subjacente do conflito utilizando estratégias de comunicação e facilitação (WIGELL, 2012).

Em relação a esse momento de fluidez que vivemos, Bauman (2001), ao explicar a relação entre modernidade e tempo/espaço, afirma que a relação entre tempo e espaço passa a ser processual, mutável e dinâmica, o que justifica a passagem da modernidade pesada (sólida) para modernidade leve (líquida), comparando a primeira a um hardware e a segunda a um software.

Assim, faz-se necessário identificar mecanismos de resolução de conflito que possam atender a essa fluidez. Para tanto, a mediação ambiental internacional pode contribuir para as necessidades atuais, que é apresentar uma resposta para a questão ambiental, mas que permita a construção de um ambiente de paz sustentável, levando em conta os contextos locais de cada conflito, de cada indivíduo, grupo ou sociedade afetada, bem como seus aspectos culturais.

É necessário verificar se a mediação pode contribuir para a conscientização de todos os atores envolvidos no conflito, enquanto agentes responsáveis pelo meio em que vivem e que será entregue para aqueles que estão por vir, a fim de confirmar se ela pode fortalecer a ética da responsabilidade, defendida pelo filósofo Hans Jonas (2015).

\section{A ética da responsabilidade e a Mediação ambiental internacional}

\footnotetext{
2 Diplomacia multi-track é um conceito desenvolvido e posto em prática por Louise Diamond e John McDonald, co-fundadores do Institute for Multi-Track Diplomacy. O conceito é uma expansão da distinção original feita por Joseph Montville em 1982, entre as abordagens da primeira faixa (ação oficial, ação governamental) e pista dois (ação não oficial, não governamental) para a resolução de conflitos.
} 
O filósofo Hans Jonas (2015) propõe o princípio da responsabilidade como um princípio ético, no qual as pessoas, ao agirem, devem fazê-lo de tal forma "que os efeitos de suas ações sejam compatíveis com a permanência de uma vida humana sobre a terra".

Trata-se de um desafio ético, o viver sustentável na contemporaneidade sugere um compartilhar de valores éticos, pelos quais sejam verificadas condições mínimas de bem-estar para gerações atuais e futuras. Assim, todas as ações humanas devem ser compatíveis com a continuidade da vida humana no futuro, todos são responsáveis pela promoção da sustentabilidade.

A sustentabilidade é um valor da contemporaneidade, que se configura a partir do amadurecer da sociedade para a compreensão da sua própria existência responsável no planeta.

Essa responsabilidade deve gerar esforços mútuos, comparada a uma rede de atores, como Estado, organizações governamentais, não governamentais, sociedade civil; cada um tem um conhecimento que pode melhorar a produtividade do outro por meio da complementariedade. Os conflitos da era pós-moderna exigem uma dinâmica e flexibilidade que um único nível de atuação não consegue produzir, dependendo da complexidade do conflito, em especial, os ambientais. Para a resolução do problema será necessário o envolvimento da esfera política, econômica e social. Muitas vezes, o mediador atuará em esferas distintas, na busca por um objetivo comum.

A mediação ambiental internacional mediação ambiental internacional pode contribuir para as necessidades atuais, que é apresentar uma resposta para a questão ambiental, mas que permita a construção de um ambiente de paz sustentável, levando em conta os contextos locais de cada conflito, de cada indivíduo, grupo ou sociedade afetada, bem como seus aspectos culturais.

A qualidade ambiental atual e futura depende de como a sociedade percebe a interação entre o uso e a exploração do meio ambiente. No caso específico dos recursos naturais, os conflitos aparecem quando se percebe um desacordo quanto ao acesso, controle e uso desses recursos. As diferenças surgem quando há uma incompatibilidade de interesses e necessidades entre as prioridades de certos grupos sociais e políticos em relação ao uso múltiplo de um recurso, como o solo, por exemplo.

Os conflitos ambientais são complexos, pois se inter-relacionam com problemas sociais e econômicos e geralmente atingem mais de um grupo de pessoas. Ademais, no 
âmbito de incidência, também podem ser geradas interações múltiplas entre as dimensões nacional, regional e internacional.

Deste modo, é importante desenvolvermos no momento atual, uma preocupação com a futura geração, uma reflexão sobre como a mediação pode contribuir para garantir uma equidade intergeracional.

A mediação constitui método baseado nos processos de negociação e também é uma forma de resposta facilmente adaptável e sensível ao contexto, que tem por marca a ampliação do processo de negociação para refletir os diferentes conflitos, participantes e situações (BERCOVITCH, 2016).

Moore (1998) define a mediação como uma "extensão e elaboração do processo de negociação. A mediação envolve a intervenção de um terceiro aceito pelas partes, imparcial, neutro e que não possui poder com autoridade de decisão, para auxiliá-las voluntariamente atingirem um acordo mútuo". A neutralidade do mediador e a falta de autoridade para tomar decisões são evidenciadas por Moore, que visualiza o mediador como aquele que auxilia voluntariamente as partes com o objetivo de atingirem soluções mutuamente aceitáveis para as questões em disputa.

A intervenção de uma terceira pessoa profissional no processo de mediação e a responsabilidade das partes na adoção das decisões são notas características de todas as definições que delineiam a mediação. Às partes pertence o protagonismo absoluto na tomada de decisões, cabendo ao mediador a organização e condução do procedimento. Nessa dinâmica, o mediador simplesmente auxilia, colabora para que as partes cheguem a uma solução, mas de um modo imparcial e ativo.

Entre os métodos de ADR (Alternative Dispute Resolutions) ${ }^{3}$, a mediação ocupa lugar central, seja pela maior flexibilidade de suas práticas, seja por sua adaptabilidade a contextos e ordenamentos jurídicos diferentes, ou seja pelo modelo de Justiça e de ordem social que transmite, conforme acentua Foddai (2010).

Baruch Bush e Folger (2010) descrevem, resumidamente, as quatro versões que marcaram a mediação, contribuindo para sua definição. Com efeito, a primeira a descreve como forma criadora de solução de problemas, a qual origina arranjos que satisfazem a todas

\footnotetext{
3 A expressão indica um conjunto de instrumentos de gestão dos conflitos sociais e de resoluções de controvérsias que se apresentam como alternativas à jurisdição do Estado. Foi criada pelo jurista americano Frank Sander, em 1976, durante a Pound Conference, realizada para sugerir uma solução ao problema do mau funcionamento da Justiça nos Estados Unidos, recorrendo a formas alternativas ou complementares de composição das disputas.
} 
as partes contendoras do conflito (história da satisfação). Na outra versão, a mediação colabora para organizar e criar coalizões entre os indivíduos, com o fim de contribuir com maior poder de negociação à parte que não tem (história da justiça social). Uma terceira resenha apresenta a mediação como fator que engendra o crescimento moral nas partes litigantes, o qual promove o surgimento de seres humanos mais fortes e compreensivos no cadinho do conflito humano (história da transformação). A quarta visão percebe a mediação como forma de aplicar pressão e manipular, de tal modo que agrava as condições de injustiça para os indivíduos que já se encontram em desvantagem (história da opressão).

Com base nessas posições, alguns pontos importantes podem ser destacados, como os de que o movimento de mediação é variado e pluralista. (BARUCH BUSH; FOLGER, 2010). O enfoque dominante da prática de mediação se concentra na resolução de problemas e na formulação de arranjos, mas pouco se enfatiza a criação de alianças ou a transformação dos antagonistas mediante a revalorização e o reconhecimento.

Uma segunda visão que surge do relato das quatro histórias é que existem diferentes opiniões acerca de que meta social deve tratar de alcançar o movimento da mediação. Vai depender da meta adotada, se terá uma orientação futura sobre o caráter do movimento.

Baruch Bush e Folger (2010) acentuam que tanto a história da justiça social como a história da opressão são promovidas por outra premissa: a meta mais importante é impulsionar a igualdade entre os indivíduos, ou inversamente, reduzir a desigualdade. Com efeito, a história da justiça social sublinha a capacidade da mediação para organizar os indivíduos ao redor dos interesses comuns e conclui que as coalizões obtidas promovem o sucesso da meta final, que é a igualdade. Já a história da opressão realça a capacidade da mediação para manipular e exercer pressão dissimuladamente e adverte que essa manipulação e dita pressão atuarão em prejuízo dos que se encontram em situação de desvantagem, e que se corre o risco de agravar a desigualdade.

Por fim, a premissa da história da transformação tem como base o fato de que a meta mais importante consiste em originar o crescimento moral e transformar o caráter humano, para obter uma força mais considerável e maior compaixão. O referido enfoque destaca a capacidade da mediação para promover a revalorização e o reconhecimento.

O processo de mediação possui características particulares, dentre as quais constitui uma extensão e uma continuação da gestão pacífica de conflitos; envolve a intervenção de um agente externo, que poderá ser um indivíduo, um grupo ou uma organização, em um conflito 
entre dois ou mais Estados ou outros atores. Também, é uma forma de intervenção não coercitiva, não violenta e não vinculante. (BERCOVITCH, 2016).

As definições expostas demonstram o amplo espectro da mediação internacional, mas não bastam para defini-la diante da interação dinâmica e complexa entre mediadores, dotados de recursos e interesses no conflito ou em sua resolução, e os protagonistas ou seus representantes. A mudança de papéis dos mediadores, em qualquer conflito ${ }^{4}$, é coerente nesse processo dialético, admitindo redefinição. As questões que constituem seu objeto podem ser alteradas, e até as partes em conflito podem se modificar. Diante disso, os mediadores atuam em um conflito para auxiliar as partes a alcançarem um resultado não obtido de outro modo, lançando mão de uma gama enorme de comportamentos para atingir seus objetivos. Nessa dinâmica, alguns fazem sugestões para um acordo, e outros evitam fazê-lo. Outros, ainda, estão interessados em atingir um acordo, e alguns outros, não necessariamente. Alguns mediadores são neutros, e outros, não, e isso não compromete a eficácia do processo. Ao contrário, se amolda às características dos conflitos internacionais.

A mediação internacional é examinada sob vários ângulos, que incluem desde pesquisas acadêmicas a recomendações políticas, passando por desenvolvimento de teorias a esse respeito, sendo certo que quatro principais tradições se formaram nesse estudo. Assim, o primeiro grupo de estudos tem, majoritariamente, nos acadêmicos associados ao Programa de Negociação da Universidade de Harvard, suas bases, oferecendo como contribuição o aconselhamento sobre o que constitui a boa gestão de conflitos em situações reais (BERCOVITCH, 2016). Fisher, Ury e Patton (2014) destacam-se, nesse segmento, com livros e manuais sobre como mediadores e negociadores devem se comportar, o que define uma boa negociação ou mediação e como os conflitos podem ser resolvidos, tendo na obra "Getting to Yes" (1981) seu exemplo melhor.

O segundo grupo apresenta como contribuição o desenvolvimento de um conjunto de regras aplicáveis a todos os conflitos, nacionais e internacionais, utilizando-se de técnicas variadas de interação e resolução de problemas, em uma combinação da ação política com a experimentação científica. O referido grupo, que tem nas figuras de Burton e Doob, entre

\footnotetext{
4 A mediação pode ser empregada em conflitos que ocorrem entre Estados, dentro de Estados, ou entre grupos de Estados, organizações e indivíduos e pode tornar-se um conflito mais complexo entre grupos étnicos.
} 
outros $^{5}$, sua grande referência, tem por suporte noções teóricas e a experiência de acadêmicos; todavia, se encontra em estágio inicial de pesquisas.

Pesquisas realizadas por economistas e seguidores da Teoria dos Jogos, que desenvolvem modelos matemáticos para examinar como pessoas se comportam em situações de conflitos cujas condições são de racionalidade e informações ótimas, formam o terceiro grupo. O exame de estratégias para realizar concessões e alcançar acordos são práticas comuns desses estudos ${ }^{6}$.

Como instrumento da diplomacia e da política externa, da promoção da paz e da expressão do direito internacional, a mediação mostra-se adequada quando um conflito é longo, duradouro ou muito complexo; quando o esforço das partes para a sua gestão chegou a um impasse; quando as partes não estão dispostas a aceitar os custos adicionais ou as mortes trazidas pelo conflito; e quando as partes estão dispostas a cooperar, tácita ou explicitamente, para romper o impasse (BERCOVITCH, 2016).

A dinâmica da mediação implica relacionamento entre um mediador e as partes em disputa com interesse político. Os mediadores são, indubitavelmente, atores políticos, e ignorar esse aspecto significa deixar de levar em conta importante característica desse instrumento.

Vários são os motivos para se desejar a mediação, dentre os quais destacam-se: o auxílio na redução de riscos da escalada do conflito e condução ao acordo; aceitação da mediação, pelas partes, na expectativa de que o mediador repreenda ou influencie o adversário; visão, pelas partes, de que se trata de uma expressão pública de seu compromisso com a norma internacional de gestão pacífica dos conflitos; habilidade do mediador para atuar no monitoramento, verificação e garantia de qualquer acordo que venha a ser criado (BERCOVITCH, 2016).

Diversos são os papéis dos mediadores, como o de catalisador, educador, tradutor, multiplicador de recursos, identificador de problemas, entre outros.

As estratégias de formulação, como a escolha do lugar do encontro, a administração do ambiente físico, a garantia da privacidade da mediação, a redução de tensões, manejo, por

\footnotetext{
5 Para melhor aprofundamento, a leitura das obras de John W. Burton, como Global Conflict. Brighton: Wheatsheaf, 1984, e de L.W. Doob, como Resolving Conflicts in Africa. New Haven: Yale University Press, 1971, são instrumentos valiosos.

${ }^{6}$ Para melhor aprofundar, a obra de H. Raiffa, denominada The Art and Science of Negotiation. Cambridge: Harvard Universitiy Press, 1982, constitui boa referência.
} 
primeiro, das questões mais simples, foco das questões em jogo, elaboração de sugestões e propostas substantivas, merecem ênfase.

Várias são as estratégias de manipulação, tendo nas práticas a seguir sua importância para o bom êxito da atuação do mediador, a saber, permanência das partes em negociação, mudança das expectativas das partes, assunção de responsabilidades por concessões feitas, ciência dos custos na hipótese de insucesso do acordo, fornecimento e filtro de informações, prestígio a concessões realizadas pelas partes, condução das partes em demonstrar flexibilidade, disponibilidade para verificação do cumprimento do acordo.

A natureza do conflito, os fatores particulares que o envolvem e os objetivos e interesses do mediador determinam as estratégias a serem empregadas. À guisa de exemplo, em conflitos de baixa intensidade, as estratégias de comunicação podem ser mais efetivas. Em contrapartida, em conflitos de alta intensidade as estratégias mais ativas e manipulativas são mais adequadas (BERCOVITCH, 2016).

A dimensão de quem pode mediar é importante para o exame da mediação, tendo em vista a ausência de uma autoridade centralizada no sistema internacional. Levando em conta a inevitabilidade dos conflitos e sua universalidade, são eles divididos em três categorias, a saber, indivíduos, Estados, instituições/organizações.

Bercovitch (2016, p. 41) define mediação individual como aquela "feita por indivíduos que não são representantes oficiais de governos ou autoridades políticas no exercício do seu cargo". Tal mediação apresenta maior variedade, é praticada com maior liberdade e consiste na mediação formal e informal. A primeira é aquela em que um representante político, como um representante de governo ou um tomador de decisão de alto nível, atua em sua capacidade individual para mediar um conflito entre representantes oficiais de outros estados. Ocorre essencialmente em uma estrutura formal, como uma conferência, um fórum político ou outros espaços oficiais, apresentando menor flexibilidade quando contrastada com a mediação informal, mas dispõe de amplo acesso a influentes tomadores de decisão. Por seu turno, a mediação informal é aquela que

se refere a esforços de mediadores que têm uma longa experiência e um profundo comprometimento com a resolução de conflitos internacionais; ou a atuação de acadêmicos reconhecidos cujas formação, atitudes e experiência profissional os habilitam a atuar na mediação de conflitos na prática (BERCOVITCH, 2016, p. 42). 
Os mediadores, nesse campo, atuam como cidadãos privados e contribuem com sua experiência acadêmica, credibilidade para facilitar a comunicação, obter uma melhor compreensão do conflito e alcançar sua resolução. Em geral, o processo de mediação informal é desencadeado pelo próprio mediador, que atua no conflito por iniciativa própria, tendo por base estratégias de comunicação e facilitação.

No que diz respeito aos Estados, eles atuam na maior parte dos processos de mediação por intermédio de seus representantes e de organizações regionais e internacionais.

Serviços de um dos tomadores de decisão de alto escalão do Estado são, em geral, requisitados para a referida atuação quando ele é convidado a mediar um conflito ou inicia uma mediação.

É importante levar em conta que a mediação, em qualquer nível e qualquer que seja a forma, é um processo essencialmente voluntário (BERCOVITCH, 2016).

Nesse sentido, para que a mediação entre Estados tenha eficácia, o mediador deve ser imparcial, aceito pelas partes e merecedor de sua confiança.

$\mathrm{Na}$ mediação entre Estados, pequenas potências têm grande envolvimento em mediações internacionais. Isso porque, quando intervém, seus esforços tendem a se concentrar em conflitos regionais e suas estratégias tendem a assumir um perfil discreto, baseado no diálogo e na comunicação (BERCOVITCH, 2016). Por seu turno, grandes potências em geral criam oportunidades para mediar conflitos, empregando a mediação como veículo para proteger ou promover seus próprios interesses, oferecendo um ambiente neutro, exercendo pressões por concessões e oferecendo propostas e incentivos para as partes envolvidas.

No entanto, a mediação conduzida por pequenas ou grandes potências não é regida pelo direito internacional, de tal sorte que a forma e características são negociadas e renegociadas a cada fase, o que não permite antever os resultados.

No sistema internacional moderno, dada a complexidade do ambiente internacional, junto aos Estados, surge crescente número de organizações internacionais e transacionais que atuam e influenciam questões afetas à paz e às guerras e que também têm participação ativa na resolução de conflitos internacionais. Entre as organizações internacionais, estão a Organização dos Estados Americanos (OEA) e a Organização das Nações Unidas (ONU), que representam Estados e têm expressiva atuação na mediação formal. Já as organizações transnacionais, como a Anistia Internacional, representam indivíduos de diferentes países e têm frequente a prática da mediação informal. 
A ONU tem pujança entre as organizações internacionais, especialmente no papel que desempenha na negociação e mediação. Com efeito, a Agenda para a Paz, subscrita pelo secretário-geral Boutros-Ghali, reforça a primazia do emprego da diplomacia preventiva, da promoção e da consolidação da paz para a Organização (ONU, 2017). Reconhece, diante das várias demandas existentes, a necessidade de descentralização e delegação, para que todas as partes da organização sejam utilizadas em sua capacidade plena. Nessa ótica, a ONU deve encorajar as organizações regionais a auxiliarem as Nações Unidas, e o secretário-geral a estimular arranjos ad hoc que darão suporte aos seus esforços, por meio de grupos informais como Os Amigos do Secretário-Geral de Salvador. Igualmente, a ONU pode buscar o envolvimento mais ativo de agentes sem vínculos com o Estado (BOUTROS-GHALI, 2012).

No âmbito das organizações regionais, têm realce as mediações coletivas, sendo certo que, em geral, a adesão aos princípios de negociação e mediação como seu principal método de resolução de conflitos é sua nota característica. A história, a cultura e a experiência compartilhadas por seus membros são componentes marcantes para sua atuação.

Como instrumento da diplomacia e da política externa, da promoção da paz e da expressão do direito internacional, a mediação mostra-se adequada quando um conflito é longo, duradouro ou muito complexo; quando o esforço das partes para a sua gestão chegou a um impasse; quando as partes não estão dispostas a aceitar os custos adicionais ou as mortes trazidas pelo conflito; e quando as partes estão dispostas a cooperar, tácita ou explicitamente, para romper o impasse (BERCOVITCH, 2016).

A responsabilidade ética em relação como bem ambiental deve gerar esforços mútuos, incentivada pela formação de uma rede de atores, como Estado, organizações governamentais, não governamentais e sociedade civil. Onde cada um tem um conhecimento que pode melhorar a produtividade do outro por meio da complementariedade. Os conflitos da era pósmoderna exigem uma dinâmica e flexibilidade que um único nível de atuação não consegue produzir, dependendo da complexidade do conflito, em especial, os ambientais. Para a resolução do problema será necessário o envolvimento da esfera política, econômica e social. Muitas vezes, o mediador atuará em esferas distintas, na busca por um objetivo comum, que é promover a dignidade e consolidar a paz para presentes e futuras gerações.

\section{CONCLUSÕES}


Na seara dos conflitos ambientais, são requeridas soluções criativas e díspares das tradicionais utilizadas, e que são insuficientes para equacionar a preservação do meio ambiente e a sobrevivência das futuras gerações.

A crise ambiental manifesta-se na perda do sentido da existência humana, e a sustentabilidade tem banalizado o seu uso. Nessa ótica, os desafios para se construir uma sociedade pós-moderna sustentável devem ter uma acepção voltada à ética da responsabilidade, que lança a mediação ambiental internacional como mecanismo de resolução de conflito flexível e de fácil adaptação à dinâmica ambiental.

$\mathrm{Na}$ sociedade pós-moderna, conflitos são frequentes, o que implica a existência de uma rede complexa de objetos e agentes, com dimensões locais, regionais e que transcendem as fronteiras de um país. Diante dessa complexa relação, a mediação ambiental, especialmente utilizada de forma preventiva, coloca-se como melhor alternativa à litigância, e o envolvimento de novos atores pode contribuir com maior legitimidade, eficácia e igualdade na solução final.

O processo inclusivo na mediação facilita a interação entre as partes em conflito e outras interessadas e cria mecanismos para compreensão de todas as perspectivas, em busca da construção de um acordo.

A mediação ambiental, seja no contexto interno ou internacional, é um mecanismo de adaptação fácil e sensível ao contexto. Permite a ampliação do processo de negociação para facilitar a reflexão dos diferentes conflitos, situações e perspectivas. É flexível, sobretudo. Além disso, fomenta a cooperação e a comunicação e faz aflorar os interesses e necessidades rumo aos acordos mutuamente satisfatórios.

Assim, a mediação ambiental internacional desponta como ferramenta de prevenção, construção e manutenção da paz, a ser utilizada por diversos atores, dada as suas características de incentivo ao diálogo, ao processo participativo, ao estímulo à cooperação, à solidariedade entre os povos e principalmente à possibilidade dos mediadores atuarem em vários níveis do conflito, formando uma rede de pacificadores.

\section{REFERÊNCIAS BIBLIOGRÁFICAS}


BAUMAN, Zygmunt. Modernidade Líquida. Trad. Plínio Dentzien. Rio de janeiro: Zahar, 2001.

BARUCH BUSCH, R. A.; FOLGER, J. P. La promesa de mediación: cómo afrontar el conflicto a través del fortalecimento propio y el reconocimiento de los otros. Buenos Aires: Granica, 2010.

BERCOVITCH, J. A. A mediação em conflitos internacionais: panorama teórico e revisão das práticas. In: HERZ, M.; SIMAN, M.; DRUMOND, P. (Org.). Mediação Internacional. Petrópolis, Rio de Janeiro: Vozes, Editora PUC-Rio, 2016. p. 26 a 56.

BOUTROS-GHALI, B. ONU: uma agenda para o desenvolvimento. 2012. Disponível em: <http://www.iea.usp.br/publicacoes/textos/boutros_ghalionu.pdf.> Acesso em: 10 jul. 2017.

CARSON, R. Primavera silenciosa. São Paulo: Gaia, 2010.

ERNANDORENA, P. R. Resoluções de conflitos ambientais no Brasil: do patriarcal ao fraternal. Estudios Sociales, México, v. 20, n. 40, 2012. Disponível em: <http://www.scielo.org.mx/scielo.php?script=sci_arttext\&pid=S0188-

$45572012000200001 \& \operatorname{lng}=e s$ \&nrm=iso>. Acesso em: 10 Jan. 2019.

FISHER, Roger; URY, Willian. Como chegar ao sim: como negociar acordos sem fazer concessões. Trad. Ricardo Vasques Vieira. Rio de Janeiro: Solomon, 2014.

FODDAI, M. A. Conciliación y mediación: ¿ modelos diferentes de resolucíon de conflictos? In: CANALES, C. F. (Coord.). Mediación, arbitraje y resolución extrajudicial de conflictos em el siglo XXI. Tomo I - Mediación. Madrid. Reus: 2010. p. 41-56.

JONAS, Hans. O Princípio Responsabilidade: Ensaio de uma Ética para a Civilização Tecnológica. Rio de Janeiro: Contraponto, 2015.

LUND, M. S. Preventing violent conflicts a strategy for preventive diplomacy. Washington, DC: United States Institute of Peace, 1999.

MARSHALL, Andrew C. States, international organizations and other actors in the world of peacemaking. In: PIIPARINEN, Touko; BRUMMER, Ville (Org.). Global networks of mediation Prospects and avenues for Finland as a peacemaker. Finlândia: Finnish Institute of International Affairs, 2012. p. 25-33.

MOORE, Christopher W. O processo de mediação: estratégias práticas para a resolução de conflitos. Trad. Magda França Lopes. 2. ed. Porto Alegre: Artmed, 1998.

NOTTER, James; DIAMOND Louise. Building peace and transforming conflict: multi-track diplomacy in practice. Occasional Paper Number 7. The Institute for Multi-Track Diplomacy, 1996. Disponível em: 〈http://imtd.imtdeast.org/papers/OP-7.pdf〉. Acesso em: 1 fev. 2017.

ONU - Organização das Nações Unidas. Departamento de Assuntos Políticos (DPA). Guidance on Gender and Inclusive Mediation Strategies. 2017. Coordination: Pouran 
Ghaffarpour. UNION, Publishing Services Section/ Nairobi. Disponível em: <http://peacemaker,un.org.node/2940>. Acesso em: 16 março 2019.

ONU - Organização das Nações Unidas. Departamento de Assuntos Políticos. United Nations Guidance for Effective Mediation. jul. 2012. Disponível em: <http://peacemaker.un.org/guidance-effective-mediation>. Acesso em: 20 jun. 2017.

KISS, Alexandre; SHELTON, Dinah. Guide to International Environmental Law. Boston: Martinus Nijhoff Publishers, 2007.

RUIZ, José Juste; DAUDI, Mireya Castillo. La protección del médio ambiente en ámbito internacional y enlaunión europea. Valência: Tirant lo Blanch, 2014.

STULBERG, J. B. The Theory and pratice of mediation: a reply to professor susskind. Vermont Law Review, [S.1], v. 6, n.1, p. 85-117, 1981.

YANG, Tseming; PERCIVAL, Robert V. The Emergence of Global Environmental Law. Ecology La W Quarterly. [S.1.], v. 36, n. 615, p. 615-664, 2009.Disponível em: <http://digitalcommons.law.scu.edu/facpubs/728.> Acesso em: 28 out. 2016.

WIGELL, Mikael. The multi-track model of peace mediation. In: PIIPARINEN, Touko; BRUMMER, Ville (Org.). Global networks of mediation Prospects and avenues for Finland as a peacemaker. Finlândia: Finnish Institute of International Affairs, 2012. p. 1624.

YOSHIDA, C. Y. M. Os desafios da mediação ambiental no Brasil. Boletim AASP, [S.1.], n. 3038, 2. quinzena maio 2017. 